\title{
A new Bergeria (Flemingitaceae) from the Mississippian of Xinjiang, NW China and its evolutionary implications
}

\author{
Ru Feng ${ }^{1,2}$, Ashalata D'Rozario ${ }^{3}$ and Jian-Wei Zhang ${ }^{2 *}$
}

\begin{abstract}
A new Bergeria (Lepidodendrales, Flemingitaceae), B. wenquanensis sp. nov., is described in this paper, typically characterized by the longest and elongated leaf cushions ever found. The specimen, collected from the Mississippian of Wenquan County, Xinjiang Uygur Autonomous Region, China, is represented by a fossil stem about two meters long, with distinct leaf cushions. The genus Bergeria has usually been assigned to partially decorticated Lepidodendron stems. Although Cathaysian Lepidodendron have been extensively reported in China, most of them were found in the central, eastern and southern parts of the country, rarely in northwestern China. This new species is so far the westernmost record and the most isolated representative from the Cathaysian Lepidodendron center. Based on the distribution of the Cathaysian Lepidodendron during the Mississippian, most of the species were in the South China Plate near the Equator, while the new species is discrete in the north, far from the Equator. According to the spatiotemporal distribution of Cathaysian Lepidodendron, this genus appeared during the Mississippian, a period which was represented by rather few species, it flourished and expanded northwards during the Pennsylvanian, taking the north block of the South China Plate as the center. Since the Cisuralian to the Guadalupian, the genus became gradually sparser in all areas of distribution, probably due to strong climate change. During the Lopingian, the genus migrated southwards to the South China block and had a broader distribution range again, and it became extinct to the end of this interval. The new species is also significant for the evolution of Lepidodendron leaf cushions. During the Mississippian, the primitive species of Lepidodendron usually had narrow, fusiform leaf cushions, while the Pennsylvanian or Permian species were more variable in shape of leaf cushions, from inverted water-drop, rhomboidal, hexagonal, trapeziform to horizontal rhomboidal.
\end{abstract}

Keywords: Cathaysian flora, Bergeria, Lepidodendron, Mississippian, Xinjiang

\section{Introduction}

The arborescent lycopsids were one of the most frequent vascular plant groups during the Late Paleozoic, including genera Lepidodendron, Lepidophloios, Sigillaria, Bothrodendron, Bergeria, Diaphorodendron and Omphalophloios, all of which are based on stem remains. For example, Lepidodendron is a stem genus of arborescent lycopsids which lived during Carboniferous-Permian interval, mainly distributed in the tropical and subtropical swamps of Euramerican and Cathaysian Floras (Cleal and Wang

\footnotetext{
* Correspondence: zhangjianwei@ms.xjb.ac.cn

${ }^{2}$ Xinjiang Institute of Ecology and Geography, Chinese Academy of Science,

Urumqi 830011, Xinjiang Uygur Autonomous Region, China

Full list of author information is available at the end of the article
}

2002; Hilton and Cleal 2007; Taylor et al. 2009). It is the major component of both Euramerican and Cathaysian Floras, but with a significant age difference. The Euramerican Lepidodendron mainly existed during the Carboniferous and became extinct to the end of the Late Pennsylvanian; their leaf cushions were characterized by spiral arrangement, and they were vertically elongated, fusiform to rhomboidal in shape (Taylor et al. 2009; Álvarez-Vázquez and Wagner 2014; Moore et al. 2014). The Cathaysian Lepidodendron appeared in the Carboniferous and persisted till the Lopingian, after the extinction of the Euramerican Lepidodendron (Taylor et al. 2009). Consequently, the Cathaysian Lepidodendron possessed a longer stratigraphic range; their leaf cushions were 
more evolved and showed more complex shapes, from simple fusiform to complex hexagons with various transitional shapes (Li 1997; Sun 1999, 2002; Fluteau et al. 2001; Taylor et al. 2009). The leaf cushions of Bergeria are similar in arrangement and shape to Lepidodendron, however, the differences are that in Bergeria, the leaf scars are not differentiated or preserved as compressions, and they rather generated impressions.

The morphology of leaf cushions are the major basis for the Lepidodendron classification (Thomas 1970; Taylor et al. 2009; Álvarez-Vázquez and Wagner 2014). For example, the leaf cushion of Lepidodendron bellii Álvarez-Vázquez et Wagner is rhomboidal in shape with a marked horizontal asymmetry, the upper and lower ends slightly inflected in opposite directions; whereas for $L$. aculeatum Sternberg, the cushion is fusiform, symmetrical, with acuminate apex and base distinctly inflected in opposite directions (Álvarez-Vázquez and Wagner 2014). The leaf cushions were mainly characterized by fusiform shapes during the Mississippian, then they emerged as rhomboidal shaped during the Late Mississippian; during the Permian, the size of leaf cushion was generally larger than the Carboniferous ones and mainly vertical rhomboidal, trapeziform, horizontal rhomboidal and lenticular in shape; during the Lopingian, the leaf cushions became more diverse, with shapes from quadrilateral to hexagonal in the Cathaysian Flora (CTPP 1974).

More than sixty fossil species of Lepidodendron were recorded in China, in the Cathaysian Flora, and they mainly occurred in central, eastern and southern China, rarely in northwestern China. In Xinjiang, NW China, only Lepidodendron kirghizicum Zalessky was reported in Fuyun County, Mississippian in age (Sun et al. 2010).
The fossil in this paper occurred in an area which is closer to Central Asia and it is so far the westernmost and the most distant from the Cathaysian Lepidodendron center. The present paper deals with the identification and detailed morphological description of the fossil, the spatial and temporal distribution, the migration routes of Cathaysian Lepidodendron and the evolutionary lines of the leaf cushion shapes during the CarboniferousPermian interval.

\section{Materials and methods}

The fossil site $\left(44^{\circ} 51.365^{\prime} \mathrm{N}, 81^{\circ} 14.134^{\prime} \mathrm{E}\right.$; Fig. 1) is located in the Lower Carboniferous outcrop in Wenquan County, Xinjiang Uygur Autonomous Region, NW China. The outcrop is characterized by clastics and carbonates of the neritic and marine-terrigenous strata of the Akeshake Formation (Fig. 2), Mississippian (late Visean) in age, which can be divided into two members. Both the upper and lower members contain abundant fossils such as brachiopods, corals, gastropods, bivalves, and foraminifers of the genus Eostaffella, whereas the plant remains are represented mainly by Sublepidodendron (Nathorst) Hirmer and common plant debris (XBGMR 1993). The current plant-fossiliferous bed is a light yellow, yellow-brown lithic arkose with black siltstone (approximately $20 \mathrm{~m}$ thick) and it occurs in the middle-lower part of the upper member.

A fossil stem examined in the present study is preserved as impressions with leaf cushions. The fossil was cleaned by the dégagement technique (Leclercq 1960) and deposited in the Repository of the Xinjiang Institute of Ecology and Geography, Chinese Academy of Sciences, Urumqi, Xinjiang Uygur Autonomous Region, China and numbered

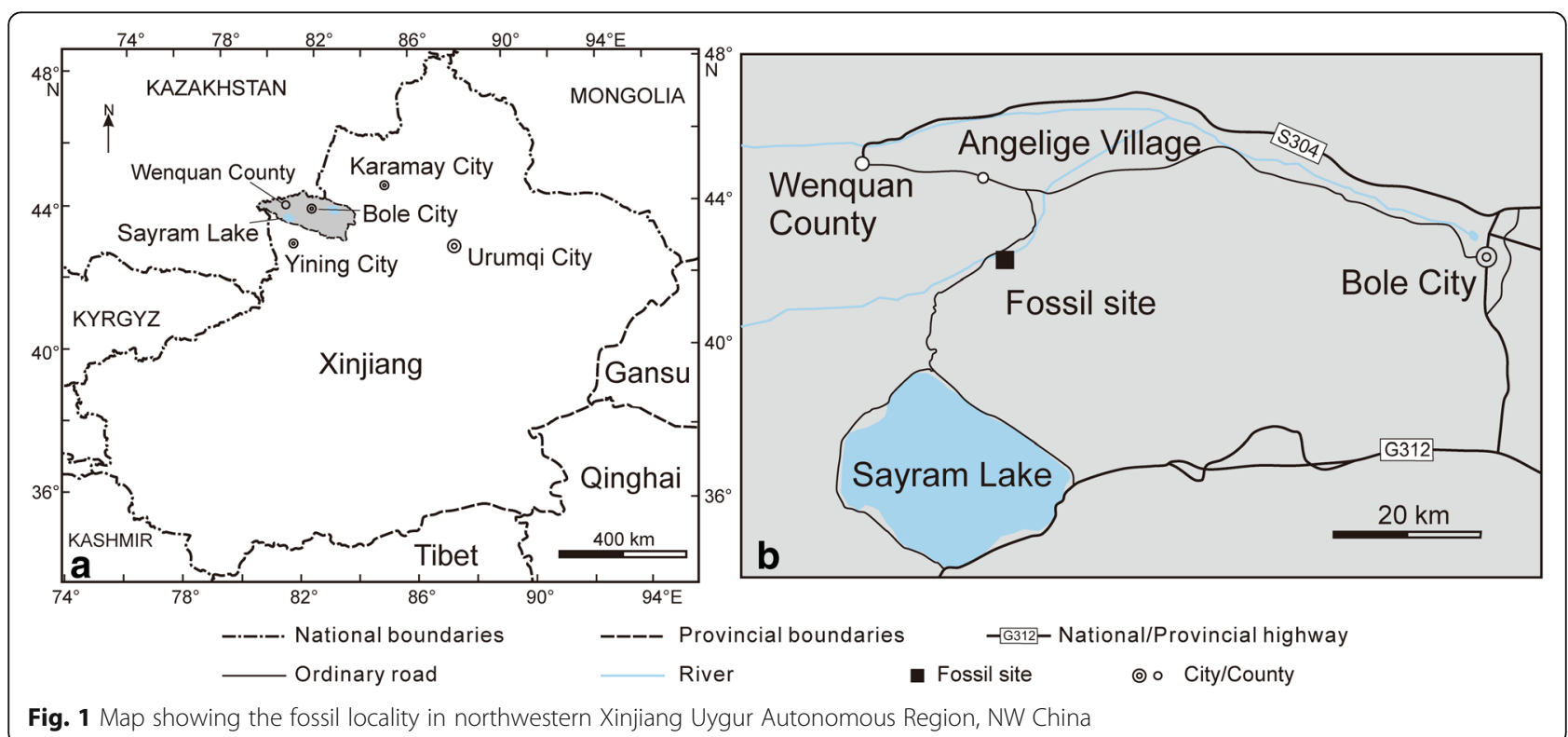




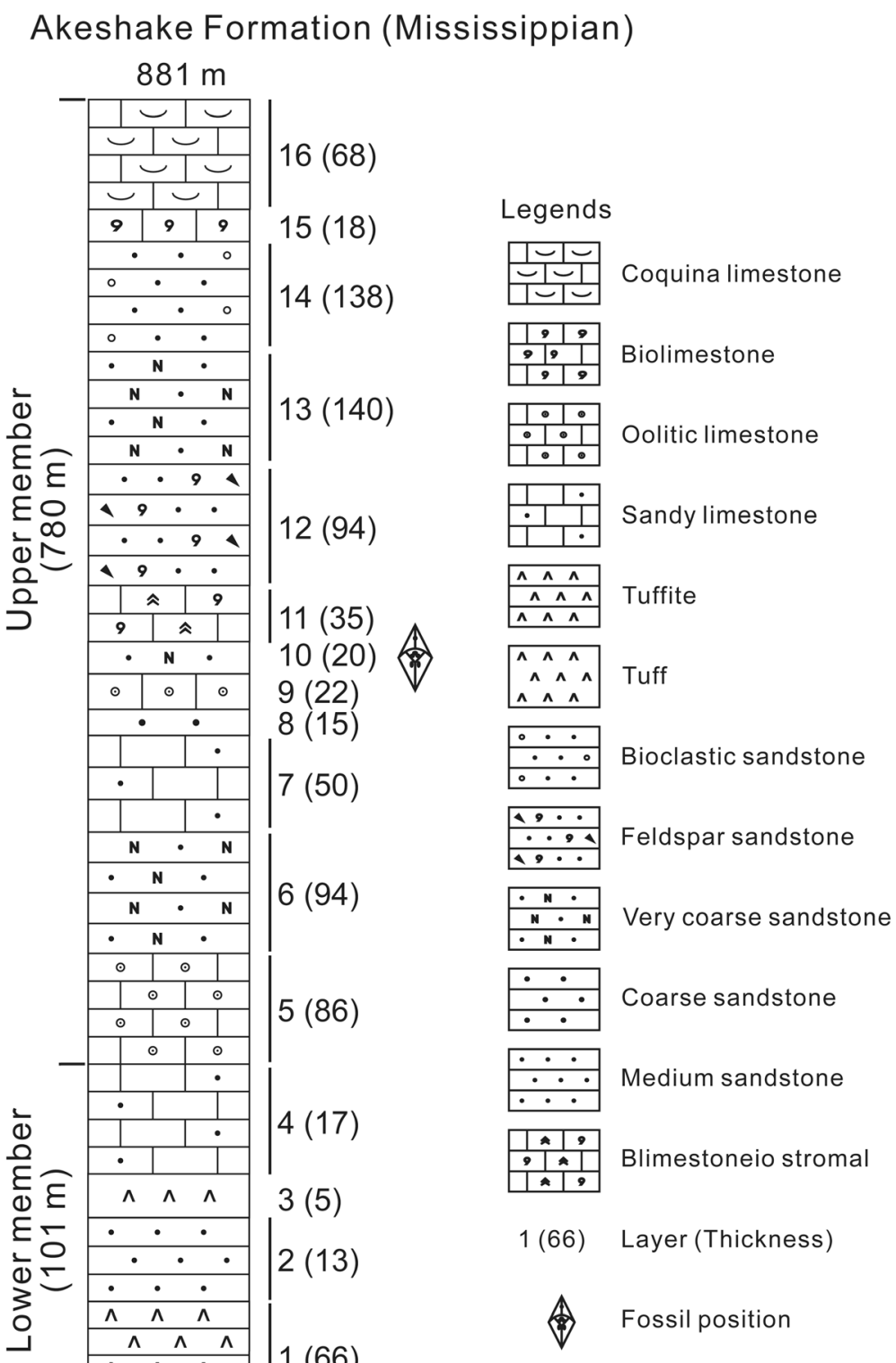

Fig. 2 Stratigraphic column of the Akeshake Formation of Mississippian (upper Visean), showing the stratigraphic position of the fossil. The vertical thickness is not to scale, with thickness of each layer marked respectively. The stratigraphic data is cited from XBGMR (1993)

as XJ2016001. The specimen was photographed with a Nikon digital camera under reflected light and adjusted in Adobe Photoshop (V.7), and the plates were prepared in Corel Draw (Ver.12). The palaeogeographic maps were prepared using ArcView GIS 3.2. All of the Cathaysian Lepidodendron fossil data were collected from Sun et al. (2010).

\section{Results}

\subsection{Systematics}

Order: Lepidodendrales.

Family: Flemingitaceae.
Genus: Bergeria Presl 1838.

Type species: Bergeria acuta Presl 1838.

Species: Bergeria wenquanensis Feng, D'Rozario et Zhang, sp. nov.

Derivation of specific epithet The specific name is derived from the name of the fossil locality in Wenquan County, Xinjiang Uygur Autonomous Region, China.

Specific diagnosis Leaf cushions narrowly fusiform or long lanceolate in shape and spirally arranged on the 
stem, contiguous or separated by narrow grooves and without a distinguished leaf scar. Upper and lower apexes acuminate and elongated to linear, not inflected in any direction. Lateral angles broadly rounded or arc-shaped; lower and upper acuminate apexes of two adjacent leaf cushions mostly staggered, occasionally connected, each side overlaps $1 / 3$ to $1 / 2$ length with its adjacent leaf cushions. Leaf cushions have visible ornamentation and fine grooves on the surface; some vertical streaks are also scattered along the leaf cushion on the lower part.

Type locality About $15 \mathrm{~km}$ south of Angelige Village $\left(44^{\circ} 51.365^{\prime} \mathrm{N}, 81^{\circ} 14.134^{\prime} \mathrm{E}\right)$, Wenquan County, northwestern Xinjiang, NW China.

Stratum tipicum and age Akeshake Formation, Mississippian (late Visean).

Repository Xinjiang Institute of Ecology and Geography, Chinese Academy of Sciences, Urumqi, Xinjiang Uygur Autonomous Region, China.

\subsection{Description}

The fossil stem (Fig. 3a) is about two meters long, elliptic in transverse section with longer diameter approximately $80 \mathrm{~mm}$ wide, its surface is covered by spirally arranged leaf cushions. From the lower to the upper part of the stem, the size of leaf cushions become gradually smaller and more closely arranged (Fig. 3a), the average density of leaf cushions is about 0.33 cushions $/ \mathrm{cm}^{2}$.

The leaf cushions are narrowly fusiform or long lanceolate in shape, its upper and lower apex elongated to linear (Fig. 3b-f), $40-70 \mathrm{~mm}$ long and 6-9 $\mathrm{mm}$ wide, with a length/width ratio of 7-8. The upper and the lower apex of a cushion is acuminate, the angle ranging between $14^{\circ}-19^{\circ}$ (Fig. 3d, f), while the lateral angles are broadly rounded or arc-shaped (Fig. 3d). The leaf cushions (Fig. 3d) protrude slightly and the most protuberant part is in the middle of a cushion.

The leaf cushions have visible ornamentation and fine grooves on the surface. In the lower-middle part of a leaf cushion occur some scattered vertical streaks (Fig. 3c). The leaf cushions have clear boundary between each other (Fig. 3e). The lower and upper acuminate apexes of the two adjacent leaf cushions are mostly staggered, occasionally connected, each side overlaps $1 / 3$ to $1 / 2$ length with its adjacent cushions (Fig. 3b-f).

\section{Discussion}

\subsection{Systematics}

The original stem morphogenera include Lepidodendron, Lepidophloios and Sigillaria, in which Lepidodendron as defined by Sternberg (1820) was recently subdivided into several genera such as Diaphorodendron, Synchysidendron, Paralycopodites (= Bergeria) and Ulodendron. Diaphorodendron and Synchysidendron were described based on the anatomically preserved specimens from coal balls (DiMichele 1985; Bateman et al. 1992; DiMichele and Bateman 1992; Phillips and DiMichele 1992; Cleal and Wang 2002; Álvarez-Vázquez and Wagner 2014; Moore et al. 2014), while Paralycopodites and Ulodendron were separated due to the absence of anatomical characters. In Diaphorodendron, the leaf cushions are flattened against the stem and there is no inter area between each other (Moore et al. 2014), these characters are absent in the present fossil and thus different. For Synchysidendron, the upper and lower angles of a leaf cushion are rounded, the leaf cushions become equidimensional on aerial axes as the stem diameter decreases (Cleal and Wang 2002; Álvarez-Vázquez and Wagner 2014; Moore et al. 2014). These features are different from those of the current fossil. The genus Ulodendron only includes the specimens with typical anatomical characters absent. The genus Bergeria, as recently described based on type of a compression form (Álvarez-Vázquez and Wagner 2014), encompasses specimens that lack a well-differentiated leaf scar, and it has usually been applied to partially decorticated lycopsid stems with lepidodendroid leaf cushions. Thus, the specimens with lepidodendroid leaf cushions would be assigned to the genus Bergeria if its leaf cushions have no clearly visible leaf scars. The current fossil, the decorticated Lepidodendron stem with no clear leaf scars, is most likely to be assigned to the genus Bergeria.

Two species of Bergeria, B. dilatata and B. worthenii have similar morphological characters with the current fossil; but $B$. dilatata has leaf cushions with small, irregular scars at or near the top of the cushion, while $B$. worthenii has the area above and below the leaf scar ornamented with coarse, transverse, discontinuous wrinkles, which are easily distinguishable from $B$. wenquanensis.

The leaf cushions of the new fossil material are narrowly fusiform in shape, with its length much longer than the width. Among Cathaysian Lepidodendron, four species have similar leaf cushion like the present fossil: L. dabieshanense Wu (Fig. 4a), L. kirghizicum Zalessky, L. ninghsiaense Sze et Lee (Fig. 4b) and $L$. szeianum Lee (Fig. 4c). However, the first three species were excluded easily due to the unmatched leaf cushion size or length/width ratio. For example, in $L$. dabieshanense, the width of leaf cushion is no more 


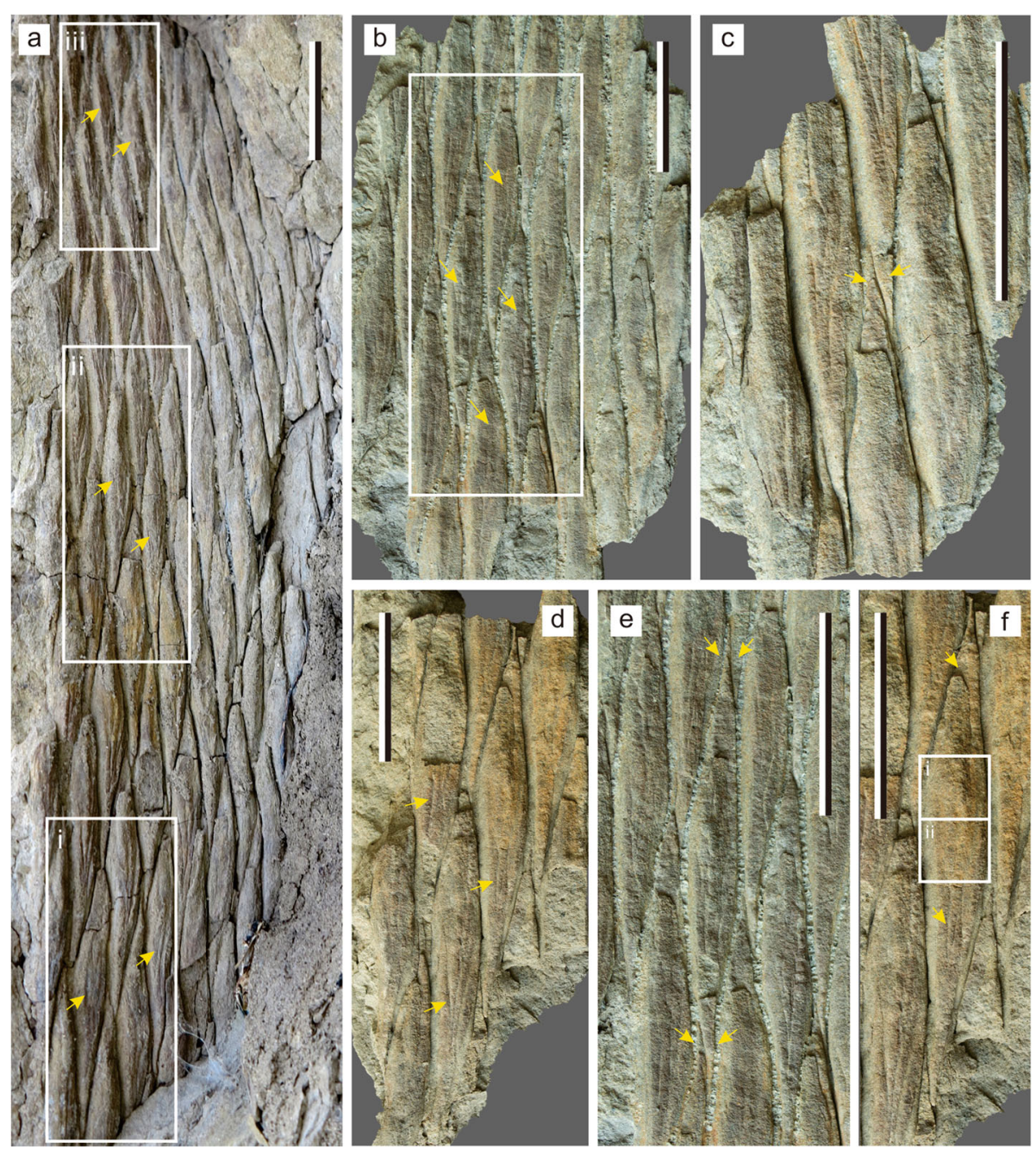

Fig. 3 Bergeria wenquanensis sp. nov. The scale bars are $3 \mathrm{~cm}$ long each. a Leaf cushions getting gradually smaller and more closely arranged from frames i to iii, arrows indicating the leaf cushions; b The relationship between the leaf cushions in the frame, lower and upper acuminate apices of two adjacent leaf cushions mostly staggered, occasionally connected (indicated by arrows); c Stagger of two adjacent leaf cushions (indicated by arrows); $\mathbf{d}$ Spiral arrangement of leaf cushions (indicated by arrows); e Enlargement of $\mathbf{b}$ showing upper and lower angles of a leaf cushion (indicated by arrows); $\mathbf{f}$ Enlargement of $\mathbf{d}$ showing protruding part of a cushion in frames $\mathrm{i}$ and ii, arrows indicating the visible ornamentation and the fine grooves on the surface of leaf cushions

than $1 \mathrm{~mm}$ (usually $0.5-1 \mathrm{~mm}$ ); in L. kirghizicum, the length of leaf cushion is no more than $10 \mathrm{~mm}$ and width no more than $2 \mathrm{~mm}$; in $L$. ninghsiaense, the length/width ratio of a leaf cushion is no more than 3 (Sun et al. 2010).

The shape and size of the leaf cushions in the current fossil is most similar to those of Lepidodendron szeianum which was found from the Upper Mississippian of Liaoning, Shanxi, Shandong and Gansu and Lower Permian of Inner Mongolia and Henan (Li 1963; Sun et al. 2010). Their leaf cushions are narrowly fusiform in shape, with a length more than twice the width; the upper and lower apexes of their cushions are acuminate. But the current fossil differs from L. szeianum clearly in the following characters: in the new fossil, the leaf cushions are narrower and long lanceolate in shape with length/ width ratio of 7-8; and the upper and lower apexes of a cushion are elongated to lines and appear like needles. In L. szeianum, the leaf cushions are fairly wider, and mostly have a length/width ratio of about 2 ; and the two ends of a cushion are not elongated or appear like needles. Moreover, in the new fossil, the leaf cushions have clear boundaries between each other; the lower acuminate apex and the upper apex of two adjacent leaf cushions are mostly staggered, occasionally connected; and each side overlaps $1 / 3$ to $1 / 2$ length with its adjacent cushions. In L. szeianum, the leaf cushions are densely arranged on the stem and have no clear boundary between each 

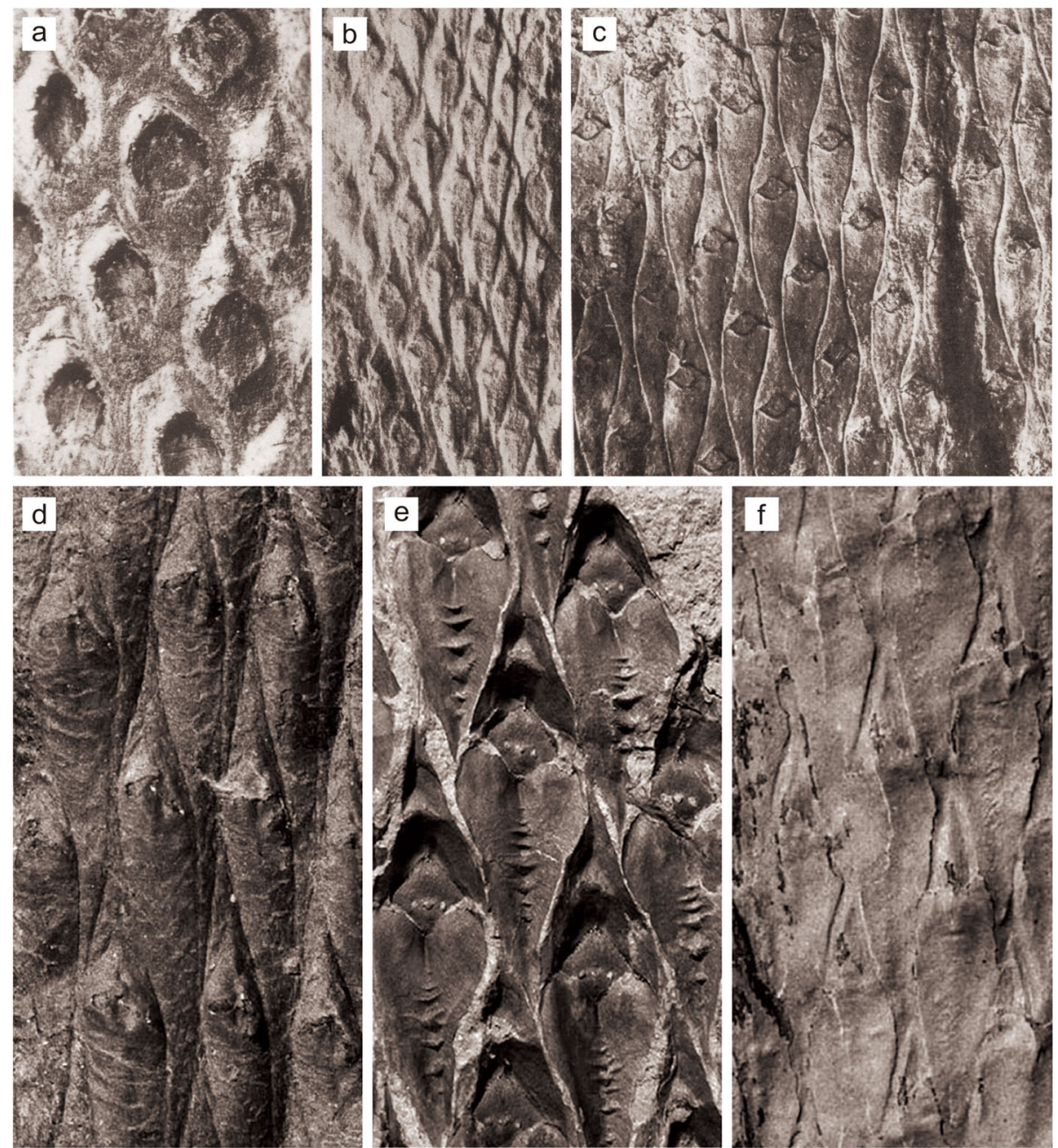

Fig. 4 Comparisons with species of genera Lepidodendron and Bergeria. a L. dabieshanense; $\mathbf{b}$ L. ninghsiaense; $\mathbf{c}$ L. szeianum; $\mathbf{d}$ B. worthenii $(\times 2)$; e L. aculeatum (× 2); $\mathbf{f} B$. dilatata (× 6). a-c and e modified from Sun et al. (2010); $\mathbf{d}$ and $\mathbf{f}$ modified from Álvarez-Vázquez and Wagner (2014)

other, the lower acuminate apex and the upper one of the two adjacent leaf cushions are mostly connected, or only slightly staggered (Sun et al. 2010).

Therefore, the new fossil from the Wenquan County cannot be assigned to any known species. It was thus designated as a new species and named as Bergeria wenquanensis.

\subsection{Spatiotemporal distribution of the Cathaysian Lepidodendron}

Based on the distributions of Cathaysian lepidodendroid plants (including the species of genus Lepidodendron and of the current Bergeria wenquanensis; Fig. 5), during the Early Mississippian, most of the species were grouped in an old land (South China Plate) near the Equator; only two Xinjiang species (Lepidodendron kirghizicum and $B$. wenquanensis) are discrete in the north and far from the Equator (Fig. 5a). Thus, the palaeoequatorial hot and humid tropical zone was probably the main distribution area of Cathaysian lepidodendroid plants during the Mississippian ( $\mathrm{Li}$ and Wu 1996; Naugolnykh and Jin 2014).

In the Middle and Late Mississippian, with the northward drift of the South China Plate, the Cathaysian Lepidodendron also expanded northwards into the Northern Hemisphere, taking the north block of the South China Plate as the center, but most of the species were still distributed near the Equator, except for L. szeianum which was distributed in the north and far from the palaeo-Equator (Fig. 5b). During this time interval, the Cathaysian Lepidodendron flourished and had the highest species diversity (Li and Wu 1996; Sun 2002; Wang and Pfefferkorn 2013).

During the Late Pennsylvanian-Cisuralian transition interval, the Euramerican Lepidodendron became extinct 

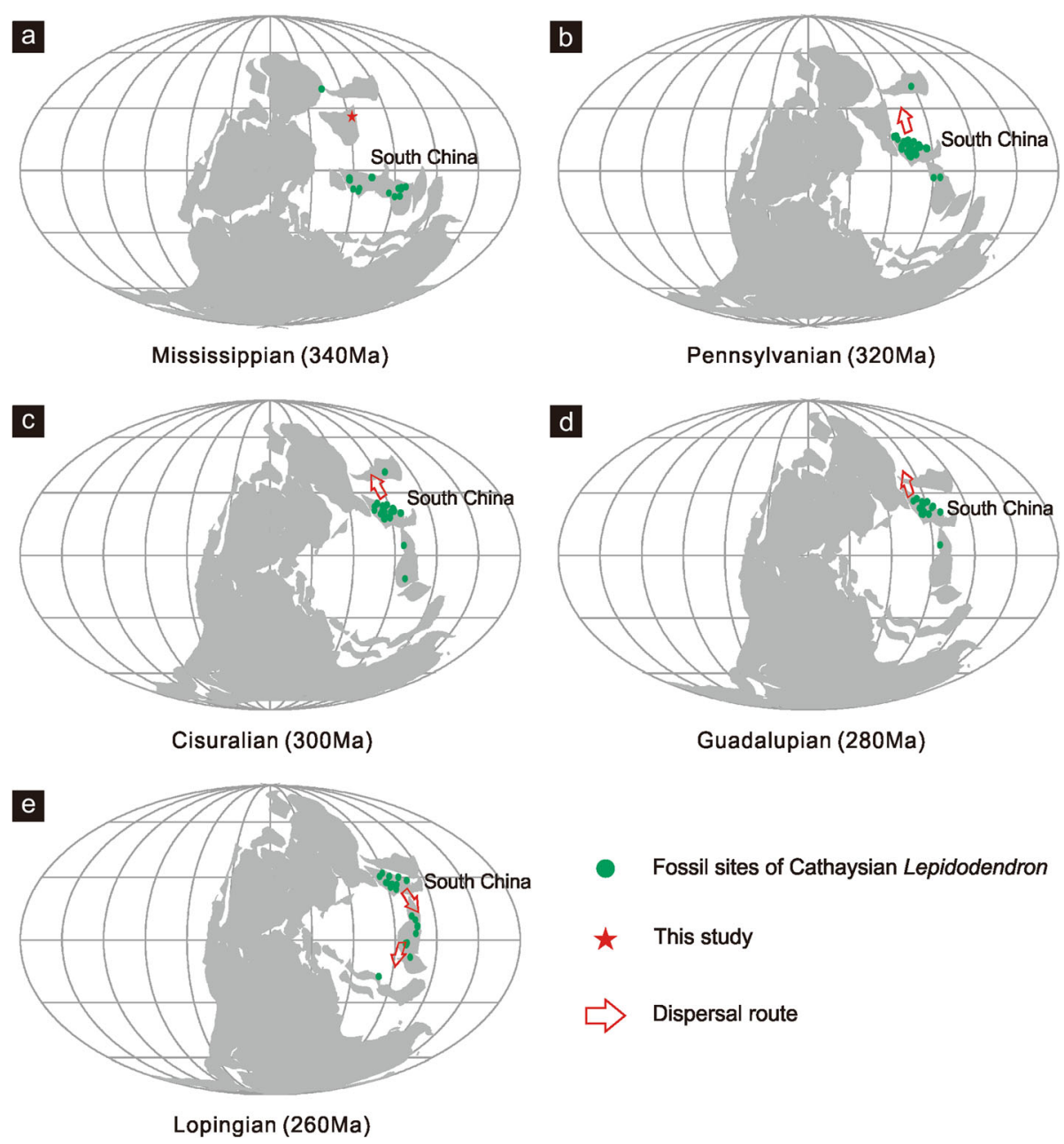

Fig. 5 Spatial and temporal distribution of the Cathaysian lepidodendroid plants

because of dry climate, but the Cathaysian Lepidodendron survived due to the persistent hot and humid climate in the Cathaysian Floral Province (Li and Wu 1996; Li 1997; Sun 1999, 2002; Cleal and Wang 2002; Hilton and Cleal 2007; Taylor et al. 2009; Cleal et al. 2009; Wang et al. 2012; Wang and Pfefferkorn 2013). Since the Cisuralian to the Guadalupian, the distribution of the Cathaysian Lepidodendron expanded northwards continuously with the northward drift of the South China Plate, and as a result, most of the species were distributed in the northern block of the South China Plate rather than near the palaeo-Equator (Fig. $5 \mathrm{c}-\mathrm{d}$ ). The fossil sites of Cathaysian Lepidodendron became sparser gradually in all distribution areas, probably due to strong climate change, related to dry conditions (Cleal and Thomas 2005; Taylor et al. 2009) or due to a glaciation (Wang 2010; DiMichele et al. 2011; DiMichele 2014).

During the Late Permian, the Cathaysian Lepidodendron ceased to expand northwards, but migrated southwards, to the southern block of the South China
Plate, obtaining a broader distribution southwards (Fig. 5e). This migration was induced by the formation of the land bridge during this time interval (Li 1997; Rigby 1998; Fluteau et al. 2001; Stevens et al. 2011; Yang and Wang 2012; Bercovici et al. 2012). To the end of the Lopingian, the Cathaysian Lepidodendron eventually became extinct (Sun 1999; Wang and Chen 2001; Rees 2002; Stevens et al. 2011).

\subsection{Evolution of leaf cushions in Cathaysian Lepidodendron}

Leaf cushions of sixty reported Cathaysian lepidodendroid species were studied. We report that the Mississippian cushions (Fig. 6a) were mainly characterized by the vertically elongated fusiform shape, representing the primitive morphological state (DiMichele and Bateman 1992). During the Pennsylvanian, the cushion shape was dominated by the rhomboidal form. Since the Late Pennsylvanian to the Cisuralian, the species of Lepidodendron 
a

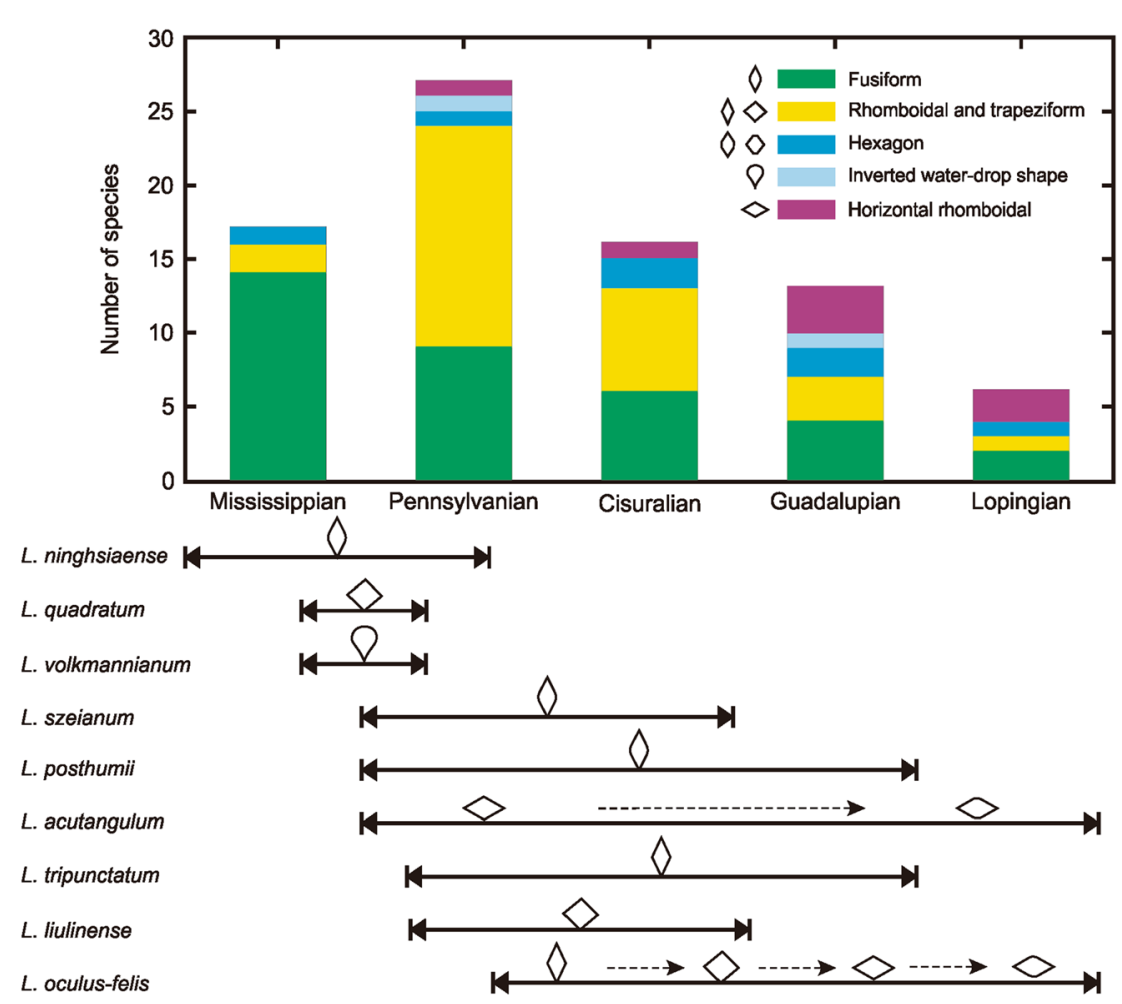

b

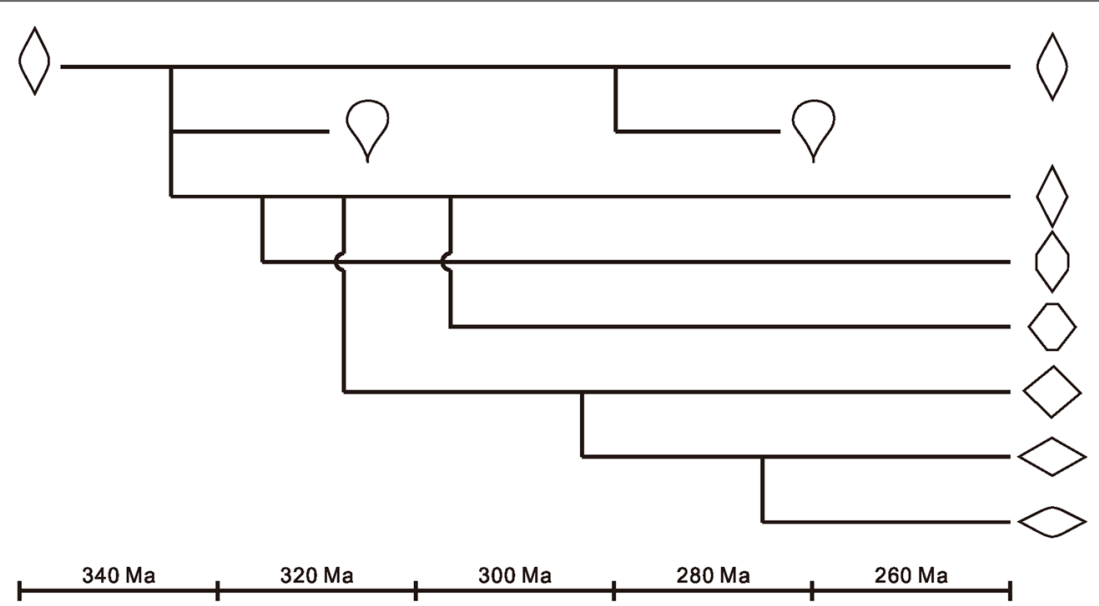

Fig. 6 Evolution of the shape of leaf cushions in Cathaysian lepidodendroid plants. a Differences in components of shapes of leaf cushions since the Mississippian to the Lopingian; $\mathbf{b}$ Ranges of the shapes of leaf cushions since the Mississippian to the Lopingian

experienced a rapid decrease, and only a few of them survived (Booi et al. 2008; Stevens et al. 2011). The cushions of these species show three types of shape: rhombus, fusiform and hexagon. The hexagonal cushion shape appeared after the fusiform and the rhomboidal shapes. During the Guadalupian, the shapes of leaf cushions are more complicated, as five types were reported (Fig. 6a). Most of the species show hexagonal leaf cushions, some other species also have fusiform, rhomboidal, inverted water-drop or horizontal rhomboidal leaf cushions.
During the Lopingian, only four types of leaf cushions were left: fusiform, rhomboidal, hexagonal and horizontal rhomboidal (Sun 1999; Wang and Chen 2001; Rees 2002; Stevens et al. 2011).

Based on this evidence, we report that the fusiform leaf cushions (represented by Lepidodendron wenquanensis or L. ninghsiaense) were the earliest during the Mississippian, then the rhomboidal (L. quadratum) and the inverted water-drop shape (L. volkmannianum) during the Late Mississippian. The trapeziform (Lepidodendron liulinense), horizontal rhombus ( $L$. 
acutangulum) and hexagonal (L. hexagonum) leaf cushions appeared during the Pennsylvanian. The Permian species had the more diverse leaf cushions than the Carboniferous species, as a new, square shape (Lepidodendron hejinense) occurred beside older types (Fig. 6b). It is significant that the cushion shape showed a consistent lineage, represented by the gradual decrease of the length/width ratio, indicating that the height of the arborescent lycopsids decreased.

\section{Conclusions}

1) The new fossil found in the Mississippian strata of Wenquan County provided so far the westernmost record of Cathaysian lepidodendroids occurring west from the Cathaysian lepidodendroid center in South China Plate. It belongs to none of the previously known species, and it was named Bergeria wenquanensis sp. nov., having the longest leaf cushions reported.

2) The representatives of the Cathaysian lepidodendroids experienced a migratory process while expanding northwards, and flourished during the Pennsylvanian. Their diversity decreased between the Cisuralian and the Guadalupian, they migrated southwards with a temporary increase of diversity, only to become extinct during the Lopingian.

3) The leaf cushion showed an evolution trend represented by the gradual decrease of the length/ width ratio, from narrow fusiform during the Mississippian to square during the Permian, with five transitional shapes including rhomboidal, inverted water-drop shape, hexagonal, trapeziform and horizontal rhomboidal.

\section{Acknowledgements}

We appreciate Prof. Mihai Emilian Popa, from the University of Bucharest, for the improvement of our manuscript and the polish of the text. This research was supported by the National Natural Science Foundation of China under the Grant 41271070 and the West Light Foundation of Chinese Academy of Sciences under Grant 2015-XBQN-B-25. The authors thank Prof. Kai-Yun Guan for the coordination of plants collection, Dr. Mei-Lin Yang and Dr. Ya Li for providing some of the references.

\section{Authors' contributions}

JWZ contributed to the conception of the study; RF contributed significantly to analysis and manuscript preparation; AD helped perform the analysis with constructive discussions. All authors read and approved the final manuscript.

\section{Competing interests}

The authors declare that they have no competing interests.

\section{Publisher's Note}

Springer Nature remains neutral with regard to jurisdictional claims in published maps and institutional affiliations.

\section{Author details}

'School of Urban and Environment Science, Huaiying Normal University, Huai'an 223300, Jiangsu Province, China. ${ }^{2}$ Xinjiang Institute of Ecology and Geography, Chinese Academy of Science, Urumai 830011, Xinjiang Uygur Autonomous Region, China. ${ }^{3}$ Department of Botany, Narasinha Dutt College, 129 Bellilious Road, Howrah 711101, India.
Received: 23 March 2018 Accepted: 18 August 2018

Published online: 08 January 2019

\section{References}

Álvarez-Vázquez, C., and R.H. Wagner. 2014. Lycopsida from the lower Westphalian (middle Pennsylvanian) of the maritime provinces, Canada. Atlantic Geology 50: 167-232.

Bateman, R.M., W.A. DiMichele, and D.A. Willard. 1992. Experimental cladistic analysis of anatomically preserved arborescent lycopsids from the carboniferous of Euramerica: An essay on paleobotanical phylogenetics. Annals of the Missouri Botanical Garden. 79 (3): 500-559.

Bercovici, A., S. Bourquin, J. Broutin, J. Steyer, B. Battail, M. Véran, R. Vacant, B. Khenthavong, and S. Vongphamany. 2012. Permian continental paleoenvironments in southeastern Asia: New insights from the Luang Prabang Basin (Laos). Journal of Asian Earth Sciences. 60: 197-211.

Booi, M., I.M. van Waveren, J.H.A. van Konijnenburg-van Cittert, and P.L. de Boer 2008. New material of Macralethopteris from the early Permian Jambi flora (middle Sumatra, Indonesia) and its palaeoecological implications. Review of Palaeobotany and Palynology 152 (3): 101-112.

Cleal, C.J., S. Opluštil, B.A. Thomas, Y. Tenchov, O.A. Abbink, J. Bek, T. Dimitrova, J. Drábková, C. Hartkopffröder, and T.V. Hoof. 2009. Late Moscovian terrestrial biotas and palaeoenvironments of Variscan Euramerica. Netherlands Journal of Geosciences 88 (4): 181-278.

Cleal, C.J., and B.A. Thomas. 2005. Palaeozoic tropical rainforests and their effect on global climates: Is the past the key to the present? Geobiology 3 (1): 13-31.

Cleal, C.J., and Z.Q. Wang. 2002. A new and diverse plant fossil assemblage from the upper Westphalian Benxi formation, Shanxi, China, and its palaeofloristic significance. Geological Magazine 139 (2): 107-130.

Compile Team of Paleozoic Plant in China of Institute of Botany, Chinese Academy of Sciences (CTPP). 1974. Fossil Flora of China, volume 1: Paleozoic Plant in China. Beijing: Science Press (in Chinese).

DiMichele, W.A. 1985. Diaphorodendron, gen. Nov., a segregate from Lepidodendron (Pennsylvanian age). Systematic Botany 10 (4): 453-458.

DiMichele, W.A. 2014. Wetland-dryland vegetational dynamics in the Pennsylvanian ice age tropics. International Journal of Plant Sciences 175 (2): 123-164.

DiMichele, W.A., and R.M. Bateman. 1992. Diaphorodendraceae, fam. Nov. (Lycopsida: Carboniferous): Systematics and evolutionary relationships of Diaphorodendron and Synchysidendron, gen. Nov. American Journal of Botany 79 (6): 605-617.

DiMichele, W.A., C.B. Cecil, D.S. Chaney, S.D. Elrick, S.G. Lucas, R. Lupia, W.J. Nelson, and N.J. Tabor. 2011. Pennsylvanian-Permian vegetational changes in tropical Euramerica. In Geology of the Pennsylvanian Permian in the Dunkard Basin: Guidebook, ed. J.A. Harper, 60-102. Washington, PA: 76th Annual Field Conference of Pennsylvania Geologists.

Fluteau, F., J. Besse, J. Broutin, and M. Berthelin. 2001. Extension of Cathaysian fora during the Permian: Climatic and paleogeographic constraints. Earth and Planetary Science Letters 193 (3-4): 603-616.

Hilton, J., and C.J. Cleal. 2007. The relationship between Euramerican and Cathaysian tropical floras in the late Palaeozoic: Palaeobiogeographical and palaeogeographical implications. Earth-Science Reviews 85 (3-4): 85-116.

Leclercq, S. 1960. Réfendage dùne roche fossilifère et dégagement de ses fossiles sous binoculaire. Senckenbergiana Lethaea 41: 483-487.

Li, X.X. 1963. Yuemengou group plant fossil in North China. Palaeontologia Sinica 148 (6): 1-185 45 plates (in Chinese).

$\mathrm{Li}, \mathrm{X.X}$. 1997. The origin, evolution and distribution of the Cathaysian Flora in East Asia. Acta Palaeontologica Sinica 36 (4): 411-422 (in Chinese with English abstract).

Li, X.X., and X.Y. Wu. 1996. Late Paleozoic phytogeographic provinces in China and its adjacent regions. Review of Palaeobotany and Palynology 90 (1): 41-62.

Moore, L.C., J. Wittry, and W.A. DiMichele. 2014. The Okmulgee, Oklahoma fossil flora, a Mazon Creek equivalent: Spatial conservatism in the composition of middle Pennsylvanian wetland vegetation over $1100 \mathrm{~km}$. Review of Palaeobotany and Palynology 200: 24-52.

Naugolnykh, S.V., and J.H. Jin. 2014. An early carboniferous flora of the Huadu locality from South China: Its taxonomic composition, paleophytogeographical position and paleoecological interpretation. Acta Geologica Sinica (English Edition) 88 (5): 1341-1351.

Phillips, T.L., and W.A. DiMichele. 1992. Comparative ecology and life-history biology of arborescent lycopsids in late carboniferous swamps of Euramerica. Annals of the Missouri Botanical Garden 79 (3): 560-588. 
Presl, K.B. 1838. The genus Bergeria. In Versuch einer geognostisch-botanischer Darstellung der Flora der Vorwelt, ed. K.M. Sternberg, vol. 2, 81-220. Prague: Johann Spurny (in German).

Rees, P.M. 2002. Land-plant diversity and the end-Permian mass extinction Geology 30 (9): 827-830.

Rigby, J.F. 1998. Upper Palaeozoic floras of SE Asia. In Biogeography and Geological Evolution of SE Asia, 1st ed., 73-82. Kerkwerve: Backhuys Publishers.

Sternberg, K.M. 1820. Versuch einer geognostisch-botanischer Darstellung der Flora der Vorwelt. Vol. 1. Prague: Johann Spurny (in German).

Stevens, L.G., J. Hilton, D.P.G. Bond, IJ. Glasspool, and P.E. Jardine. 2011. Radiation and extinction patterns in Permian floras from North China as indicators for environmental and climate change. Journal of the Geological Society 168 (2): 607-619.

Sun, K.Q. 1999. Origin, evolution and extinction of Cathaysia flora. Chinese Science Bulletin 44 (2): 100-107.

Sun, K.Q. 2002. The Cathaysia flora and its comparison with global contemporaneous floras. Earth Science Frontiers 9 (3): 73-84 (in Chinese with English abstract).

Sun, K.Q., J.Z. Cui, and S.J. Wang. 2010. Fossil Flora of China, volume 2: Fossil Pteridophytes in China. Beijing: Higher Education Press (in Chinese).

Taylor, T.N., E.L. Taylor, and M. Krings. 2009. Paleobotany: The biology and evolution of fossil plants (second edition), 265-293. London: Academic Press.

Thomas, B.A. 1970. Epidermal studies in the interpretation of Lepidodendron species. Palaeontology 13 (1): 145-173.

Wang, J. 2010. Late Paleozoic macrofloral assemblages from Weibei coalfield, with reference to vegetational change through the late Paleozoic ice-age in the North China block. International Journal of Coal Geology 83 (2): 292-317.

Wang, J., and H.W. Pfefferkorn. 2013. The carboniferous-Permian transition on the North China microcontinent - Oceanic climate in the tropics. International Journal of Coal Geology 119: 106-113.

Wang, J., H.W. Pfefferkorn, Y. Zhang, and Z. Feng. 2012. Permian vegetational Pompeii from Inner Mongolia and its implications for landscape paleoecology and paleobiogeography of Cathaysia. Bloomington, Proceedings of the National Academy of Sciences of the United States of America 109 (13): 4927-4932.

Wang, Z.Q., and A.S. Chen. 2001. Traces of arborescent lycopsids and dieback of the forest vegetation in relation to the terminal Permian mass extinction in North China. Review of Palaeobotany and Palynology 117 (4): 217-243.

Xinjiang Bureau of Geology and Mineral Resources (XBGMR). 1993. Regional Geology of Xinjiang Uygur Autonomous Region (Geological Memoirs of Ministry of Geology and Mineral Resources of the People's Republic of China, (1) Regional Geology, no. 32), 145-147. Beijing: Geological Publishing House (in Chinese).

Yang, G.X., and H.S. Wang. 2012. Yuzhou Flora - A hidden gem of the middle and late Cathaysian Flora. Science China Earth Sciences 55 (10): 1601-1619.

\section{Submit your manuscript to a SpringerOpen ${ }^{\circ}$ journal and benefit from:}

- Convenient online submission

- Rigorous peer review

- Open access: articles freely available online

- High visibility within the field

- Retaining the copyright to your article

Submit your next manuscript at $\boldsymbol{\nabla}$ springeropen.com 